\section{Socio-demographic profile of child and adolescent users of oral health services in Victoria, Australia}

\author{
Perfil sociodemográfico de crianças e adolescentes \\ usuários de serviços públicos de cuidado de saúde \\ bucodental em Victoria, Austrália
}

\author{
Perfil sociodemográfico de niños y adolescentes \\ usuarios de servicios públicos de atención en salud \\ bucodental en Victoria, Australia
}

Rodrigo J. Mariño 1,2

Hanny Calache 3

Martin Whelan 3

\author{
1 Melbourne Dental School, \\ University of Melbourne \\ Melbourne, Australia. \\ 2 Oral Health Cooperative \\ Research Centre, Carlton, \\ Australia. \\ 3 Dental Health Services \\ Victoria, Carlton, Australia \\ Correspondence \\ R. J. Mariño \\ Melbourne Dental School, \\ University of Melbourne. \\ Melbourne, Victoria - 3010 \\ Australia. \\ rmarino@unimelb.edu.au
}

\begin{abstract}
The aim of this study was to investigate the socio-demographic characteristics of the eligible population of users of public oral health care services in the Australian state of Victoria, aged 17 years or younger. The study was conducted as a secondary analysis of data collected from July 2008 to June 2009 for 45,728 young clients of public oral health care. The sample mean age was 8.9 (SD: 3.5$)$ years. The majority (82.7\%) was between 6 and 17 years of age, and 50.3\% were males. The majority (76.6\%) was Australianborn and spoke English at home (89.1\%). The overall mean DMFT was 1.0 (SD: 2.1) teeth, with a mean dmft of 3.16 (SD: 5.79) teeth. Data indicate that, among six year olds in the Significant Caries Index (SiC) category, the mean dmft was 6.82 teeth. Findings corroborate social inequalities in oral health outcome and provide suggestions for oral health services to develop strategies and priorities to reduce inequalities in health and well-being, and better coordinate and target services to local needs.
\end{abstract}

Oral Health; Dental Health Services; Child; Adolescent

\section{Resumo}

O objetivo deste estudo foi investigar as características sociodemográficas de usuários do serviço público de saúde bucal no Estado de Vitória, Austrália, com até 17 anos de idade. O presente estudo é uma análise de dados secundários de 45.728 sujeitos que recorreram ao serviço público de saúde bucal entre julho de 2008 a junho de 2009. A idade média da amostra foi 8,9 (DP: 3,5) anos. A maioria dos sujeitos (82,7\%) apresentava entre 6 e 17 anos de idade e 50,3\% eram do gênero masculino. A maioria (76,6\%) havia nascido na Austrália e falava inglês em casa (89,1\%). $O$ índice CPOD médio foi 1,0 (DP:2,1) e o ceod 3,16 (DP: 5,79). Os dados indicam que entre as crianças de 6 anos categorizadas no Significant Caries Index (SiC), o índice ceod médio foi 6,82. Os achados demonstram desigualdade social nos desfechos de saúde bucal e fornecem sugestões para que os serviços de saúde bucal desenvolvam estratégias e prioridades para reduzir tais desigualdades na saúde e bem-estar, de forma a adequar os serviços às necessidades locais.

Saúde Bucal; Serviços de Saúde Bucal; Criança; Adolescente 


\section{Introduction}

Early access to dental care and preventive care has been reported to be cost-effective, however a lack of access to regular dental care can compromise timely oral health care for patients and contribute to rising health care costs, as individuals postpone treatment until it becomes an emergency 1 . Oral health care delivery in Australia is largely based on private dental practice. Nonetheless, in all Australian states and territories government owned dental clinics located in Community Health Centres or at Dental Hospitals, are the backbone of Australia's health care safety net. Public dental services serve as the provider for patients who cannot access care elsewhere, through publicly employed dentists working in government clinics.

Beneficiaries of public dental services have to compete for access on a "first-come-first-served" basis. In some states, a small fee or co-payment applies to eligible groups requiring public dental services. At the same time, most public dental services have long waiting times, and face other demands, including increased expectations, addressing cultural and ethnic diversity, and oral health emergencies. Consequently, oral health care services in Australia are mainly provided by private dentists, in a fee-for-service model.

In the Australian state of Victoria public oral health services provide care to the following eligible young people (0-17 years) groups 2 :

- All children aged 0-12 years.

- Adolescents aged 13-17 years who are health care or pensioner concession card holders or dependents of concession card holders.

- All children and young people in residential care provided by the Children, Youth \& Families Division of the Department of Human Services.

- All youth justice clients in custodial care.

- All refugees and asylum seekers.

In Australia, there is a considerable body of research on the utilization of public oral health services focusing on Australian children using data sources from State health services 3,4,5. Nonetheless, no recent report is available on the oral health status of children living in the Australian state of Victoria. A recent report on children's oral health status does not include data from the two most populated Australian states, New South Wales and Victoria, thus any inference would be inaccurate 6 . Updating information on the eligible population profile is important, as their characteristics and oral health needs change over time. As an initial step towards providing this knowledge, this study investigates the sociodemographic characteristics, as well as a profile of the oral health needs of young users of public oral health care services in Victoria, from whom data, including dental status, was fully recorded at the time of the study. Additionally, a review of the users of public oral health services is important at a time when we see a decline in the overall caries rate, because it highlights those groups at risk of the disease. Thus, in order to bring attention to those individuals with the highest caries scores, the study also aimed at describing the dental caries experience in a sample of public patients and exploring Significant Caries Index (SiC) 7 for six year old public patients in Victoria. This information will provide an understanding of the effectiveness of the various strategies used to increase access by the eligible population to the available services; and should provide valuable guidance for policy makers in developing policies and funding proposals aimed at increasing access to oral healthcare services.

In line with many western countries, Australia, and particularly the state of Victoria, is a multicultural society. Victoria is composed of numerous cultural groups: indigenous people, recent immigrants and established immigrants have all come to settle in Victoria, along with their descendants, who coexist within a larger, predominant culture, creating multi-cultural and multiracial societies. Thus, issues related to who uses oral health services in the Victoria public health system can be translated/or applied to other western countries with multi-cultural societies.

\section{Methodology}

\section{Sample}

The study was conducted as a secondary analysis of data collected from July 2008 to June 2009 for the eligible population aged 17 years or younger, who attended Victorian community oral health care services that had implemented the DMF Index data base, which was being rolled out throughout the State at the time. Consequently, our study population consisted of a convenience sample of 45,728 public clients. Data came from 67 clinics (out of 84 across the state), which were then grouped into the nine health regions. The regions include five rural areas (Barwon, Grampians, Loddon, Hume and Gippsland) and four from metropolitan Melbourne (Western, Eastern, Southern and Northern). Ethics approvals were obtained from Dental Health Services Victoria (DHSV) and the University of Melbourne Human Research Ethic Committees.

Clients of public dental services, as part of the admission procedure, had to complete a form, which included selected clients' socio- 
demographic characteristics. De-identified data for public services were provided by DHSV. From this data, selected variables have been considered in this study, including:

- Socio-demographic: age, gender, aboriginality, type of health care card. Age was measured at the time of the examination and regrouped into three groups: 0 to 6 ; 7 to 12 ; and 13 and older.

- Aboriginality. In Australia, those who are of Aboriginal or Torres Strait Islander descent, identify as an Aboriginal or Torres Strait Islander, and those accepted as such by the community in which you live, or formally lived, are considered of Aboriginal or Torres Strait Islander heritage. However, Aboriginal or Torres Strait Islander heritage is something that is personal and a person does not need a "letter of confirmation" to identify him/herself as an Indigenous person 8 . Aboriginality was coded as "Yes/No".

In Australia, there are different types of concession and health care cards. Each card has its own eligibility requirements and concessions. A health care card gives access to public health care services and less expensive medicines. Children under the age of 18 who are concession card holders or dependents of concession card holders receive public dental care free of charge 9 . The type of card was coded as: "Pensioner Concession Card", "Health Card", and "Non-health Card Holder".

- Immigration: country of birth, coded as "Australia" and "Other" and language spoken at home coded as "English" and "Other than English".

- Region: region was classified according to the location of the agency where the client received dental care, as Rural areas (Barwon, Grampians, Loddon, Hume and Gippsland) and Urban areas (Western, Eastern, Southern and Northern) from metropolitan Melbourne.

Clinical measures considered in this assessment included:

- Coronal dental caries: decayed, missing, and filled surfaces (DMFS/dmfs); decayed, missing and filled teeth (DMFT/dmft) indices. The "dmft" and the dmfs are the equivalent indices for the primary dentition.

- Reason for visit was derived from the DHSV code for the type of care under which the DMF score was recorded. These codes were reclassified either as "Emergency" or "General treatment".

- Caries risk. Defined as the probability that an individual will develop, at least, a carious lesion during a specified period of time. DHSV recommends the following classification for early childhood, and Preparatory and Grade 1 children 10: "Low Risk" where the dmfs is less than half the child's age; and "High Risk" where the dmfs is greater than the child's age. For children and ado- lescents, DHSV has adopted a modified version of the American Academy of Pediatric Dentistry (AAPD) caries-risk assessment tool 11. This tool is based on clinical conditions (e.g. 4 or more visible cavities), environmental characteristics and general health conditions.

- To complement and further explore dental health status, two indices were computed:

a) the restorative unmet normative needs index, to measure restorative needs by dividing the sum of carious surfaces by the sum of carious and filled surfaces - [DS/(DS + FS)] 12,13.

b) the $\mathrm{SiC}$, the mean DMFT/dmft of the one third of the study group with the highest caries score 7 . The mean DMFT/dmft for this subgroup were calculated using the online program available at the World Health Organization (WHO) collaborating center 7 .

Clinical data was derived from dental examinations conducted by uncalibrated oral health professionals working in community dental clinics across Victoria. Therefore, no intra or inter-examiners reliability data are available. The use of general practitioners to collect epidemiological data has been investigated previously as a possible alternative to conventional surveys of adult dental health. Those results indicated that data collected from public health records are not decisively inferior to those obtained from examinations by trained and calibrated examiners 14,15 .

\section{Analysis}

The analysis provides descriptive information on the sample's demographic characteristics and oral health status characteristics. Due to the large size of the sample and to avoid results without clinical significance, there was no attempt to determine whether statistically significant differences existed among users in terms of socio-demographic and clinical characteristics. However to better understand the relationship between the combination of socio-demographic variables and $\mathrm{SiC}$, the probability of a six year old being in the $\mathrm{SiC}$ group was explored utilizing a stepwise logistic regression analysis (LRA) using gender, type of health card, course of care, region of residence, and for those not born in Australia, language spoken at home (English vs. Other) as predictors. Data manipulation and analyses were conducted using SPSS PC, version 20.0 (IBM Corp., Armonk, USA).

\section{Results}

This convenience sample comprised a total of 45,728 young Victorians who used dental public 
services between July 2008 and June 2009 in public dental clinics that had implemented the dental status (DMF) database and for whom DMF was fully recorded at the time this study commenced. The number of clients in the sample was higher in regions of Melbourne than rural location $(57.2 \%$ vs. $42.5 \%$, respectively). Of the total sample, one third (33.5\%) were dependent children of pensioner concession cardholders, and another third $(33.1 \%)$ were health care cardholders. The remaining $33.4 \%$ were non-card holders.

The average age of the sample was 8.9 years (SD: 3.5$)$. The largest proportion of clients (82.7\%) was between 6 and 17 years. Just above half of the sample $(50.3 \%)$ were male. The majority $(76.6 \%)$ were born in Australia. Clients nominated 141 different countries of birth including Australia. Most commonly reported countries other than Australia included Vietnam, China, U.K. and New Zealand. In the same manner, the majority (89.1\%) reported speaking English at home. Clients nominated 98 different languages, including English. Most frequently reported languages spoken at home other than English were: Vietnamese (19.7\%); Chinese languages (17.2\%); Arabic (9.6\%); and Dari (5.2\%).

Young indigenous clients made up 1.1\% ( $\mathrm{n}=$ 511) of the total sample. From this group, almost two thirds $(\mathrm{n}=381)$ resided in rural regions (74.6\%), while very few Indigenous youngsters were included in the sample in Metropolitan Melbourne.

The great majority of sample cases $(92.4 \%)$ were entered using the code for general treatment across the nine Victorian regions. No differences in this proportion were found by gender or by age subgroups (0-5 years vs. 6-17 years). By region, the sample in rural regions had a comparatively higher proportion of course of care entered as emergencies (8.5\%; vs. $7.0 \%$, respectively).

Overall, $32.7 \%$ of children and adolescents in the sample were classified, according to DHSV caries risk criteria, in the high risk category. Although generally similar by gender a lower proportion of non-card holders was classified as high risk to dental caries than card holders (30.9\% vs. $33.7 \%$, respectively). By country of birth, those born overseas were more likely to be classified in the high risk category compared to those Australian-born (36.2\% vs. $31.7 \%$, respectively). No difference was found between rural and urban areas in proportion of clients classified as high risk. However, by individual region, those living in the Western Region, Loddon and Hume Region, had a comparatively higher proportion of clients classified as high risk $(49.6 \%$; $39.8 \%$, and $37.8 \%$, respectively). On the other hand, the
Northern Region had the lowest proportion of clients classified as high risk (18.8\%). By aboriginality, more than half $(54.4 \%)$ of aboriginal clients in the sample were classified in the high risk category, while only $32.5 \%$ of non-aboriginal clients were classified in that category. By course of care category, $37.8 \%$ of those classified in the high risk group were entered under the emergency code, whereas $32.3 \%$ of them were entered under the general services code.

Findings indicated that about one third of the sample $(36.1 \%)$ had no dental caries experience $(\mathrm{DMFS}=0$ and $\mathrm{dmfs}=0$ ). This proportion decreased from $43 \%$ at 5 years to $36 \%$ at 12 years, and to $22 \%$ among 17 year olds. The dmfs and DMFS index ranged from 0 to 88 tooth surfaces and from 0 to 94 tooth surfaces, respectively. In the primary dentition, the mean value of the dmfs index for the sample was 3.2 (SD: 5.8). By dmfs components, participants had a mean of 1.4 (SD: 3.1) filled surfaces and a mean of 1.4 (SD: 3.7) decayed surfaces. The overall mean dmft score for the sample was 3.74 (SD: 3.49). Children and adolescents in the sample had an average of 0.8 (SD: 0.5) deciduous teeth missing due to caries. The overall mean caries index scores for the sample are presented in Table 1.

In the permanent dentition, the mean DMFT value for the sample was 1.0 (SD: 2.1) tooth. That is, an average of one tooth with dental caries experience. When considering the tooth surface as the unit of study, a mean DMFS value of 1.6 (SD: 4.1) tooth surfaces was observed. By DMFS component, participants had a mean of 0.7 (SD: 2.0) filled surfaces and a mean of 0.6 (SD: 1.7) decayed surfaces. Additionally, children and adolescents in the sample had an average of 0.1 (SD: 0.5) permanent teeth missing due to caries.

The results also revealed that, among those with restorative needs (i.e., dmfs $>0$ ), $43.3 \%$ had unmet restorative needs in the combined deciduous and permanent dentition. The average participant in the sample had about $60 \%$ of his/ her restorative needs unmet. On the other hand, $22.3 \%$ had at least half of their restorative needs unmet. Among those with unmet needs, the average number of decayed surfaces was 4.3 deciduous surfaces and 0.2 permanent surfaces.

\section{Significant Caries Index}

The present data indicates that the 12 year-olds in this sample had a mean DMFT of 1.57 (SD: 2.10 ) teeth. In this group of children $44.7 \%$ had no dental caries experience. Our data indicates that the one third of the group with the highest caries scores (SiC Index) among 12 year olds has a mean DMFT of 3.9 teeth. 
Distribution of mean scores for decayed, filled and missing tooth surfaces (DMFS/dmfs) and teeth (DMFT/dmft) in the permanent and primary dentitions, decayed and filled tooth surfaces and missing teeth permanent dentitions by selected socio-demographic variables. State of Victoria, Australia.

\begin{tabular}{|c|c|c|c|c|c|c|c|}
\hline & DMFT & DMFS & $\begin{array}{l}\text { Decayed } \\
\text { surfaces }\end{array}$ & $\begin{array}{c}\text { Filled } \\
\text { surfaces }\end{array}$ & $\begin{array}{l}\text { Missing } \\
\text { teeth }\end{array}$ & $\mathrm{dmft}$ & dmfs \\
\hline \multicolumn{8}{|l|}{ Age group (years) } \\
\hline $0-5$ & & & & & & $2.21(3.45)$ & $3.85(7.52)$ \\
\hline $6-12$ & 0.75 (1.39) & $1.13(2.64)$ & $0.45(1.25)$ & $0.49(1.40)$ & $0.04(0.35)$ & $2.02(2.67)$ & $3.71(5.73)$ \\
\hline $13-17$ & 3.15 (3.59) & $5.46(7.63)$ & $1.63(3.03)$ & $2.19(3.67)$ & $0.33(1.08)$ & $0.08(0.46)$ & $0.16(1.13)$ \\
\hline \multicolumn{8}{|l|}{ Health card type } \\
\hline Health Care Card & $1.24(2.38)$ & $2.05(4.79)$ & $0.70(1.93)$ & $0.82(2.22)$ & $0.11(0.61)$ & $1.69(2.79)$ & $3.10(5.91)$ \\
\hline Non-card & $0.51(1.17)$ & $0.78(2.37)$ & $0.26(0.89)$ & $0.36(1.26)$ & $0.03(0.34)$ & $1.77(2.58)$ & $3.11(5.24)$ \\
\hline Pensioner & $1.30(2.38)$ & $2.11(4.68)$ & $0.73(1.93)$ & $0.86(2.29)$ & $0.11(0.61)$ & $1.74(2.77)$ & $3.27(6.18)$ \\
\hline \multicolumn{8}{|l|}{ Region } \\
\hline \multicolumn{8}{|l|}{ Rural } \\
\hline Barwon & $1.42(2.57)$ & $2.20(4.65)$ & $0.64(1.87)$ & $1.13(2.67)$ & $0.09(0.50)$ & $2.03(2.98)$ & $3.86(6.84)$ \\
\hline Gippsland & $0.84(2.00)$ & $1.41(4.21)$ & $0.51(1.64)$ & $0.48(1.64)$ & $0.09(0.59)$ & $1.73(2.70)$ & $3.11(5.51)$ \\
\hline Grampians & $1.26(2.52)$ & $2.00(4.82)$ & $0.44(1.73)$ & $1.14(2.67)$ & $0.09(0.57)$ & $2.06(2.89)$ & $3.71(6.05)$ \\
\hline Hume & $0.98(1.98)$ & $1.68(4.41)$ & $0.46(1.35)$ & $0.67(1.87)$ & $0.11(0.65)$ & $1.91(2.91)$ & $3.46(6.36)$ \\
\hline Loddon & $1.19(2.35)$ & $1.82(4.24)$ & $0.86(2.34)$ & $0.66(1.87)$ & $0.06(0.42)$ & $1.77(2.75)$ & $3.40(6.18)$ \\
\hline \multicolumn{8}{|l|}{ Urban } \\
\hline Eastern & $0.93(1.98)$ & $1.58(4.05)$ & $0.38(1.24)$ & $0.79(2.23)$ & $0.08(0.55)$ & $1.45(2.48)$ & $2.60(5.17)$ \\
\hline Northern & $0.99(2.17)$ & $1.71(4.39)$ & $0.65(2.00)$ & $0.58(1.81)$ & $0.10(0.60)$ & $1.26(2.27)$ & $2.07(4.09)$ \\
\hline Southern & $0.79(1.62)$ & 1.17 (2.99) & $0.57(1.53)$ & $0.41(1.33)$ & $0.04(0.37)$ & $1.74(2.61)$ & $3.06(5.21)$ \\
\hline Western & $1.15(2.15)$ & $1.98(4.83)$ & $0.59(1.51)$ & $0.77(2.19)$ & $0.13(0.69)$ & $1.89(2.94)$ & $3.63(6.57)$ \\
\hline \multicolumn{8}{|l|}{ Language category } \\
\hline English & 1.01 (2.09) & $1.63(4.12)$ & $0.56(1.67)$ & $0.68(2.00)$ & $0.08(0.53)$ & $1.64(2.61)$ & $2.97(5.54)$ \\
\hline Other than English & $1.06(2.06)$ & $1.79(4.36)$ & $0.62(1.71)$ & $0.68(1.97)$ & $0.10(0.60)$ & $2.49(3.36)$ & $4.72(7.39)$ \\
\hline \multicolumn{8}{|l|}{ Country of birth } \\
\hline Australia & $0.99(2.08)$ & $1.60(4.09)$ & $0.55(1.67)$ & $0.68(1.96)$ & $0.08(0.52)$ & $1.65(2.60)$ & $2.97(5.48)$ \\
\hline Other & $1.08(2.09)$ & $1.79(4.32)$ & $0.62(1.69)$ & $0.70(2.10)$ & $0.10(0.58)$ & $2.01(3.04)$ & $3.77(6.66)$ \\
\hline \multicolumn{8}{|l|}{ Gender } \\
\hline Male & $0.92(1.96)$ & 1.49 (3.85) & $0.53(1.65)$ & $0.62(1.86)$ & 0.07 (0.49) & $1.83(2.80)$ & $3.37(6.05)$ \\
\hline Female & $1.11(2.20)$ & $1.80(4.41)$ & $0.60(1.69)$ & $0.75(2.12)$ & $0.09(0.58)$ & $1.64(2.63)$ & $2.95(5.51)$ \\
\hline \multicolumn{8}{|l|}{ Payor } \\
\hline Emergency & $0.93(2.06)$ & $1.64(4.22)$ & $0.43(1.65)$ & $0.79(2.10)$ & $0.08(0.54)$ & $2.30(3.08)$ & $4.43(7.06)$ \\
\hline General & $1.02(2.09)$ & $1.65(4.14)$ & $0.58(1.67)$ & $0.67(1.98)$ & $0.08(0.53)$ & $1.69(2.68)$ & $3.06(5.66)$ \\
\hline
\end{tabular}

Among six year olds, the mean dmft was 2.77 (SD: 3.40). However, our data indicates that the group of six year olds who were carrying the burden of the dental disease experience had a mean dmft of 6.82 teeth. By risk category, $59.6 \%$ of those classified in the high risk category were in the $\mathrm{SiC}$ category, while $28.3 \%$ of those classified in the low risk category were in the $\mathrm{SiC}$ category.

The probability of a six year old being in the $\mathrm{SiC}$ group was explored utilizing a logistic regression analysis. After controlling for the other independent variables included in the model, type of card, and language spoken at home and region were significant predictors of being in the SiC group $\left[\chi^{2}(10)=223.1 ; p<0.0001\right]$. Children in the sample born overseas, but who spoke English at home were less likely to be in the $\mathrm{SiC}$ group (adjusted OR $=0.33$; 95\%CI: 0.26-0.41). By type of card, compared to those with no health card holders, health care card holders' children in the sample (adjusted OR $=1.78$; 95\%CI: 1.45 2.19) and dependents of pensioner card holders (adjusted OR $=2.08$; 95\%CI: $1.70-2.55$ ) were more likely to be in the $\mathrm{SiC}$ group. By region of 
residence, six year olds in the sample living in rural regions were more likely to be in the $\mathrm{SiC}$ group than those living in urban region (adjusted OR = 1.67; 95\%CI: 1.41-1.98) (Table 2). The variance explained by the full model for being in the $\mathrm{SiC}$ group was $6.7 \%$ (Nagelkerke $\mathrm{r}^{2}=0.067$ ).

\section{Discussion}

Data from DHSV and agencies' registers in 2008/ 2009 show that 45,728 children and adolescents in Victoria who used dental public services met the selection criteria for this study. The majority $(82.7 \%)$ of these clients were aged between 6 and 17 years. That is, children and adolescents of school age. This age-group is more susceptible to developing dental caries in the permanent teeth that erupt during this stage. Nonetheless the large number of visits made by children aged between 1 and 5 is a cause of concern. Present data indicate that there were $7,890(17.3 \%)$ children with dental problems early in life.

In Australia, as in many countries, over the last 25 years there has been a significant decline in the prevalence of dental caries among children and young people ${ }^{3}$. However, these improvements do not mean that oral health stopped to be a priority. The WHO 16 has set goals with respect to oral health that have to be met for this age group. In this regard, compared with the target of $50 \%$ of six year olds with no dental caries proposed by WHO in 2000 17, the values for 5-6 year old children in this sample are well below this target. This highlights the need for assessment and treatment including preventive care at an earlier age than school age. Furthermore, comparing present findings with the $2000 \mathrm{Aus}$ tralian Child Dental Health Survey, the average $\mathrm{dmft}$ and DMFT appear to have increased by $35 \%$ and $200 \%$, respectively. The mean six year old dmft value found in this sample (2.77 teeth) is worse than that reported in the 2000 Children Dental Health Survey [2.00 (SD: 2.96) teeth]. In the same manner, the mean 12 year old DMFT of 1.57 teeth is higher than that of 1.07 DMFT reported previously for 12 year olds in Victoria 18 . However, the data from the present study may not be representative of the State population.

The new WHO oral health goal proposes that, by 2015 , the SiC Index should be less than 3 DMFT among 12 year olds 19. Focusing attention on the children who have substantial caries experience ( $\mathrm{SiC}$ Index) will lead to significant gains for society and for the people concerned, and would allow targeted socially appropriate public health measures aimed at avoiding and controlling disease. SiC values for 12 year old children in this sample (3.9 DMFT) were higher than the Australian average (2.4 DMFT) (5) and higher that the WHO target for 2015. There is no WHO target for the SiC levels for dmft of primary teeth for 5-6 year olds 20 . However, the SiC values for six year old children in this sample (6.82 dmft), are again higher than the Australian average for that age $(4.65 \mathrm{dmft}){ }^{4}$. In addition, it seems that current DHSV caries risk assessment criteria may need to be reviewed. For example,

Table 2

Regression coefficient, adjusted odds ratios and 95\% confidence interval for odds ratios for the factors predicting the Significant Caries Index category among 6-year-old users of public dental health services in Victoria, Australia.

\begin{tabular}{|c|c|c|c|}
\hline & $\beta$ coefficient & Adjusted OR * & $95 \% \mathrm{Cl}$ \\
\hline \multicolumn{4}{|l|}{ Health card type } \\
\hline Non-card holder & & & 1.00 \\
\hline Health Care Card & 0.576 & 1.78 & $1.45-2.19$ \\
\hline Pensioner & 0.732 & 2.08 & $1.70-2.55$ \\
\hline \multicolumn{4}{|c|}{ Not born in Australia; language spoken at home } \\
\hline Other than English & & & 1.00 \\
\hline English & -1.124 & 0.33 & $0.26-0.41$ \\
\hline \multicolumn{4}{|l|}{ Region } \\
\hline Urban & & & 1.00 \\
\hline Rural & 0.513 & 1.67 & $1.41-1.98$ \\
\hline Constant & -1.373 & & \\
\hline
\end{tabular}

95\% $\mathrm{Cl}$ : 95\% confidence interval; OR: odds ratio.

* Multivariate logistic regression, adjusting for the other factors shown in the table. 
a substantial proportion of those classified as being in the high risk group $(40.4 \%)$ were not in the $\mathrm{SiC}$ category, and almost one third of those classified as being in the low risk category were in the $\mathrm{SiC}$ category.

More importantly, despite the potential health consequences, the proportion of unmet restorative needs for this population was high (60\%). This proportion may reflect their level of social and material deprivation in a group already facing economic or social disadvantages. However it might also be a reflection of their level of awareness, expectations and need for oral health care services. Regardless of the reasons, they are avoidable, they may lead to emergency visits and incomplete treatments, and they are costly to the individual and to society 21 .

The results of this study need to be considered in light of its limitations. For example, present findings only reflect the demographic and clinical characteristics of $40 \%$ of the total number of children and adolescents $(n=114,320)$ who used public dental services during this period. As such, this analysis permits only an approximation of the true profile. Additionally, the use of region as a group variable, could give rise to an ecological fallacy and result in spurious assumptions. Nonetheless, while our data may have limitations, we believe that due to the size of our sample and the breadth of data collection, the results of this study represent a substantial contribution to oral health research in several ways. Guided by this information, community oral health care services might work with their communities to develop strategies to address priorities in oral health (for example, review the caries risk criteria guidelines and protocols for management of patients at high risk to dental caries), reduce inequalities in health and wellbeing, and better coordinate and target services to local needs.

Furthermore, service utilization information provides information about known demand. This description will not provide a complete picture of the demand for services, as there are groups in the community that have not attempted to access, or are unable to access, services. Additionally, missing from this study was the opportunity to generate qualitative data on the younger users or their parents/tutors' oral health experience. This data would provide a broader understanding of their perception and ideas. Thus, the information presented needs to be supplemented by comparing this utilization with information about the need for services derived from com- munity profiles. Further exploration of non-user groups would provide information on how to reach these groups and overcome barriers to oral health care.

Inequalities in oral health are still a major public health issue. While there is some disagreement on how inequalities operate, use of dental health services is one of the pathways 22 , understanding geographic (rural vs. urban) as well as economic (using type of health card as proxy for income) variations in health outcomes provides important inputs for health care provision and policy making 23 . Additionally, using language spoken at home as a proxy of acculturation suggest that the cultural construct might have a link with the oral health experience. Because cultural factors do not affect all members of a group in the same way, the examination of the acculturation experience is crucial for providing culturally competent services and programs 24 .

Moreover, a description of inequalities in oral health does not provide a solution 23 . To fully understand these inequalities it may be necessary to move away from a disease-focus to one that addresses social issues that influence health and well-being 25 . In this way, this study represents an additional step towards our understanding of inequalities in oral health outcomes among dental public health care users and highlights the need of specific interventions and programs to achieve health equity and to reduce disparities in oral health. Service provision in terms of vulnerable patients needs to be coordinated to ensure equity in access to health services. Access to oral health services is critical as regular dental visits provide opportunities for early diagnosis and treatment of disease and conditions, as well as for health promotion, oral hygiene education, prevention of more serious oral health-related events and maintenance of good oral health status 26 . Dentistry has a critical role to play in addressing health disparities, because inequalities in oral health mirror those of general health and persist throughout life into old age 27,28 . A broad appreciation of the consequences of oral diseases will provide a powerful tool for advocacy for oral health care resources for this diverse population group; it will also position oral health in the broader concept of personal and social well-being. With this information, health providers in Australia and elsewhere can most appropriately target programs and policies to reduce disparities in access to preventive services and treatment for all. 


\section{Resumen}

El objetivo de este estudio fue describir las características sociodemográficas de la población de usuarios de los servicios públicos de atención odontológica, de 17 o menos años de edad, en el estado australiano de Victoria. El estudio realiza un análisis secundario de los datos de 45.728 pacientes que asistieron a los servicios de atención odontológica públicos entre julio 2008 y junio 2009. El promedio de edad de la muestra fue 8,9 (s.d. 3,5) años. La mayoría (82,7 \%) tenía entre 6 y 17 años de edad, y el 50,3\% fue de sexo masculino. La mayoría $(76,6 \%)$ nació en Australia y hablaba inglés en casa (89,1\%). El COPD promedio fue 1.0 (s.d. 2.1) dientes, con un ceod promedio de 3,16 (s.d. 5,79) dientes. A los 6 años de edad en la categoría de Índice de Caries Significativo, el dmft promedio fue de 6.82 dientes. Los resultados confirman desigualdades sociales en salud bucodental y proporcionan sugerencias para los servicios de salud bucodental, con el fin de desarrollar estrategias y prioridades tendientes a la reducción de desigualdades en salud y bienestar.

Salud Bucal; Servicios de Salud Dental; Niño; Adolescente

\section{Contributors}

R. J. Mariño contributed in the analysis, interpretation of data and writing of the manuscript. H. Calache contributed in the analysis, interpretation of data and writing of the manuscript. M. Whelan contributed in the data collection and analysis, and interpretation of data.

\section{Acknowledgments}

This research was supported by funding from Dental Health Services Victoria (DHSV) Research \& Innovation Grants.

\section{References}

1. Davis EE, Deinard AS, Maïga EW. Doctor, my tooth hurts: the costs of incomplete dental care in the emergency room. J Public Health Dent 2010; 70:205-10.

2. Dental Health Services Victoria. Who is eligible. http://www.dhsv.org.au/public-dental-services/ who-is-eligible/ (accessed on 11/Apr/2013).

3. Dental Statistics and Research Unit, Australian Institute of Health and Welfare. The Child Dental Health Survey, Victoria 1999. Canberra: Australian Institute of Health and Welfare; 2001. (AIHW Cat. No. DEN 87).

4. Armfield JM, Roberts-Thomson KF, Slade GD, Spencer AJ. Dental health differences between boys and girls: The Child Dental Health Survey, Australia 2000. Canberra: Australian Institute of Health and Welfare; 2004. (Dental Statistics and Research Series, 131) (AIHW Cat. no. DEN 131).

5. Armfield JM, Roberts-Thomson KF, Spencer AJ. The Child Dental Health Survey, Australia 1999: trends across the 1990s. Adelaide: The University of Adelaide; 2003. (AIHW Dental Statistics and Research Series, 27) (AIHW Cat. No. DEN 95).
6. Ha DH, Amarasena N, Crocombe L. The dental health of Australia's children by remoteness: Child Dental Health Survey. Canberra: Australian Institute of Health and Welfare; 2013. (AIHW Dental Statistics and Research Series, 63) (AIHW Cat. no. DEN 225)

7. World Health Organization. Global oral health data bank. http://www.mah.se/CAPP/Methods-andIndices/for-Caries-prevalence/Significant-CariesIndex/ (accessed on 11/Apr/2013).

8. Department of Human Services, Australian Government. Concession and health care cards. http:// www.humanservices.gov.au/customer/subjects/ concession-and-health-care-cards (accessed on 17/Jan/2014).

9. Australian Institute of Aboriginal and Torres Strait Islander Studies. Confirmation of Aboriginality. http://www.aiatsis.gov.au/fhu/aboriginality.html (accessed on 17/Jan/2014).

10. Tinanoff N, Douglass JM. Clinical decision making for caries management in children. Pediatr Dent 2002; 5:386-92. 
11. American Academy of Pediatric Dentistry Council on Clinical Affairs. Policy on use of a caries-risk assessment tool (CAT) for infants, children, and adolescents. Pediatr Dent 2008-2009; 30(7 Suppl): 29-33.

12. DiAngelis AJ, Rojas AJ. Dental caries and periodontal disease in an Indochinese refugee population. J Dent Res 1982; 61:1233-5.

13. Todd R, Gelbier S. Dental caries and dental attendance patterns in Vietnamese children aged 11-12 years resident in three inner London boroughs, UK. Community Dent Health 1991:8:163-5.

14. Hausen H, Kärkkäinen S, Seppä L. Caries data collected from public health records compared with data based on examinations by trained examiners. Caries Res 2001; 35:360-5.

15. Clarkson JE, Worthington HV, Holloway PJ. Adult dental surveys: a different approach. Community Dent Health 1995; 12:65-9.

16. Hobdell M, Petersen PE, Clarkson J, Johnson N. Global goals for oral health 2020. Int Dent J 2003; 53:285-8.

17. Aggeryd T. Goals for oral health in the year 2000: cooperation between WHO, FDI and the national dental associations. Int Dent J 1983; 33:55-9.

18. Armfield JM, Roberts-Thomson. The Child Dental Health Survey, Victoria 2000. Canberra: Australian Institute of Health and Welfare; 2003. (AIHW Cat. no. DEN 199).

19. Bratthall D. Introducing the Significant Caries Index together with a proposal for a new global oral health goal for 12-year olds. Int Dent J 2000; 50:378-84
20. Namal N, Yüceokur A, Can G. Significant caries index values and related factors in 5-6-year-old children in Istanbul, Turkey. East Mediterr Health J 2009; 15:178-84.

21. Horey D, Naksook C, McBride T, Calache H. Why is he not smiling: the Dental Costs Study Final Report. Melbourne: Health Issues Centre; 2008.

22. Listl S. Income-related inequalities in dental service utilization by Europeans aged 50+. J Dent Res 2011; 90:717-23.

23. Rosenthal T. Geographic variation in health care. Annu Rev Med 2011; 63:493-509.

24. Mariño R, Stuart GW, Wright FAC, Minas H, Klimidis S. Acculturation and dental health among Vietnamese living in Melbourne, Australia. Community Dent Health 2001; 29:107-19.

25. Hartley DA. Rural health disparities, population health, and rural culture. Am J Public Health 2004; 94:1675-8.

26. Dolan TA, Peek CP, Stuck AS, Beck JC. Functional health and dental service use among older adults. J Gerontol A Biol Sci Med Sci 1998; 53:M413-8.

27. Watt RG. From victim blaming to upstream action: tackling the social determinants of oral health inequalities. Community Dent Oral Epidemiol 2007; 35:1-11.

28. Acheson D. Independent inquiry into inequalities in health report. London: The Stationery Office; 1998.

Submitted on 11/Apr/2013

Final version resubmitted on 20/Feb/2014

Approved on 21/Feb/2014 